STUDI

FRANCESI

\section{Studi Francesi}

Rivista quadrimestrale fondata da Franco Simone

190 (LXIV | I) | 2020

Varia - fasc. I - gennaio-aprile 2020

\title{
BRÎNDUȘA GRIGORIOU, Talent/maltalent. La culture des émotions au seuil de la littérature française
}

\section{Elisabetta Barale}

\section{(2) OpenEdition}

\section{Journals}

\section{Édition électronique}

URL : https://journals.openedition.org/studifrancesi/22152

DOI : $10.4000 /$ studifrancesi.22152

ISSN : 2427-5856

\section{Éditeur}

Rosenberg \& Sellier

\section{Édition imprimée}

Date de publication : 1 avril 2020

Pagination : 141

ISSN : 0039-2944

\section{Référence électronique}

Elisabetta Barale, «BRîndUSA GRIGoRIou, Talent/maltalent. La culture des émotions au seuil de la littérature française », Studi Francesi [En ligne], 190 (LXIV | I) | 2020, mis en ligne le 01 avril 2020, consulté le 03 août 2021. URL : http://journals.openedition.org/studifrancesi/22152 ; DOI : https://doi.org/10.4000/ studifrancesi.22152

Ce document a été généré automatiquement le 3 août 2021

\section{(c) $($ ) $(9)$}

Studi Francesi è distribuita con Licenza Creative Commons Attribuzione - Non commerciale - Non opere derivate 4.0 Internazionale. 


\title{
BRÎNDUȘA GRIGORIOU, Talent/maltalent. La culture des émotions au seuil de la littérature française
}

\author{
Elisabetta Barale
}

\section{RÉFÉRENCE}

BRÎNDUȘA GRIGORIOU, Talent/maltalent. La culture des émotions au seuil de la littérature

française, Turnhout, Brepols, 2018, «Culture et société médiévales» 32, 330 pp.

1 Réédition d'un volume publié il y a sept ans en Roumanie (Talent/Maltalent: Émotionologies liminaires de la littérature française, Craiova, Universitaria, 2012), cet ouvrage présente une relecture des premiers monuments de la littérature en ancien français (Cantilène de sainte Eulalie, Vie de saint Alexis, Chanson de Roland, Roman de Thèbes) à la lumière des travaux sur la culture des émotions entamés en 1985 par les historiens américains Peter N. et Carol Z. Stearns. Dans la Préface (pp. 9-14), Claudio GALDERISI explique que, afin d'adapter le concept moderne d'émotionologie au contexte médiéval, B.G. «joue avec bonheur et prudence de l'abolition de la bonne distance critique» (p. 9). En effet, l'ouvrage montre la capacité de l'A. d'associer les bonnes pratiques herméneutiques au plaisir de la réécriture à travers la création d'un parcours intellectuel qui se déploie en trois étapes. Les textes médiévaux sont d'abord soumis à une analyse littéraire focalisée sur les modalités d'expression des affects: en s'appuyant sur une bibliographie riche et variée (pp. 307-330), l'A. se sert du binôme lexical talent / maltalent pour examiner les sentiments, les humeurs et les désirs des personnages fictionnels. Ensuite, elle propose un essai de translatio studii par le biais de laquelle les émotions de base sont relues à l'aide des critères propres à l'histoire de la sensibilité: le style émotionnel, la communauté émotionnelle, les normes du sentiment et les émotifs, c'est-à-dire les énoncés ou les gestes susceptibles de changer l'état affectif des actants. Enfin, à l'instar de Michel Zink qui, dans Bienvenue au Moyen Âge (Paris, 2015), offre une 
relecture à la fois sérieuse et fantaisiste de quarante chroniques, elle imagine les monologues que les héros des récits auraient pu prononcer pour mettre en scène leurs émotions et qui constitueraient donc le reflet des coordonnées émotives de la société médiévale.

2 Après une brève introduction (pp. 33-45), l'ouvrage est structuré en trois sections, chacune divisée en trois chapitres. La première (pp. 49-63) consiste en une réflexion générale portant sur les valeurs de l'écriture, de la véridicité et de la littérature au Moyen Âge; les deux suivantes, bien plus articulées, présentent l'étude du corpus.

3 La deuxième section (pp. 67-216) s'arrête sur les émotions éprouvées par les hommes devant Dieu dans les œuvres hagiographiques et dans la chanson de geste. Pour commencer, l'A. se penche sur la figure de sainte Eulalie qui incarne l'émotionologie de la Passion avec la traduction du silence en élévation spirituelle. Le portrait de saint Alexis s'enchaîne sur la même ligne: le jeune homme fonde sa sainteté sur la désobéissance et sur le refus de l'émotionologie génétique représentée par son père; froid par souci de vertu, il adopte en revanche une émotionologie virginale et cherche à la transmettre à sa femme. Une relecture de la Chanson de Roland achève cette partie, car l'A. affirme que le héros épique «compte toujours susciter l'émerveillement dans une climat quasi hagiographique» (p. 127); deux hommes - Charlemagne et Roland - et deux femmes - Aude et Bramidoine - sont passés au crible de l'analyse des styles émotionnels dans le but de dresser un bilan affectif de la geste.

4 La troisième section (pp. 219-293) est entièrement consacrée au Roman de Thèbes et examine les émotions des couples devant Dieu. L'A. se concentre d'abord sur ÆEdipe et Jocaste: elle suggère que le style émotionnel de la mère privilégie l'attachement naturel à l'enfant et, lorsque la vérité de l'inceste est dévoilée, il se décline en une attitude sage et conformiste; au contraire, Ædipe, pénétrant et cruel, est hanté par un désir de purification l'amenant à l'auto-punition. Les fils de l'inceste - Étéocle et Polynice forment un couple caractérisé par le maltalent, la vergogne, mais aussi par l'orgueil et la cruauté qui les poussent à se faire la guerre; au contraire, les filles - Antigone et Ismène - relèvent d'une émotionologie aimante qui s'exprime pourtant selon des normes du sentiment différentes: Antigone souhaite garder sa virginité pour l'heure du mariage alors qu'Ismène préfère aimer sans réticences.

5 En conclusion (pp. 295-306), les œuvres analysées semblent manifester une désacralisation progressive des affects; si la veine hagiographique ne se perd pas dans la chanson de geste, elle s'estompe dans le récit romanesque où Dieu ne persiste qu'en tant qu'acte émotif littéraire, et les filles de Jocaste s'abandonnent à l'érotisme aussi bien qu'aux aspirations spirituelles. B.G. exprime enfin le souhait de poursuivre les études dans le domaine de l'émotionologie en élargissant son corpus aux récits idylliques, aux Romans de Tristan, aux fabliaux et aux mythes de la Genèse à la Renaissance. 